\title{
V5. IMPACTO DA VACINA PNEUMOCÓCICA CONJUGADA 10 VALENTE SOBRE A MENINGITE PNEUMOCÓCICA NO ESTA- DO DO RIO DE JANEIRO.
}

Evelin da Silva Munan ${ }^{1}$; Mayara Daher Pacheco ${ }^{1}$; Itacirema de Oliveira Bezerra $^{1}$; Fátima Regina Moura Azevedo ${ }^{1}$.

${ }^{1}$ Secretaria de Estado de Saúde do Rio de Janeiro.

INTRODUÇÃO O pneumococo é a segunda principal causa de meningite bacteriana no Brasil, estando também relacionado às pneumonias e septicemias. Possui mais de 90 sorotipos capsulares que podem causar a Doença Pneumocócica (DP) invasiva e não invasiva. A DP, causada pelo Streptococcus pneumoniae (pneumococo), possui significativa morbidade e mortalidade, justificando o estabelecimento de ações eficazes na prevenção da mesma, destacando-se a imunização ativa. No Brasil, as crianças de até 2 anos de idade são as mais acometidas pela meningite pneumocócica (MP). Dessa forma, baseado na magnitude, letalidade e incidência da DP invasiva, o Ministério da Saúde (MS) introduziu em 2010 no calendário nacional de vacinação a vacina pneumocócica conjugada 10 valente (PNM10), que protege contra dez sorotipos do pneumococo. Frente à introdução da PNM10 no calendário nacional de vacinação, para crianças menores de 2 anos, torna-se essencial avaliar a incidência e letalidade da MP antes e após a introdução da vacina.

OBJETIVO Analisar o impacto da vacina PNM10 sobre as taxas de incidência e letalidade da MP no grupo de menores de 2 anos no estado do Rio de Janeiro. Metodologia: Foram analisados os casos confirmados e óbitos por MP registrados no banco Sinan por faixa etária, referente ao estado do Rio de Janeiro entre 2007 e 2014, a fim de comparar as médias das taxas de incidência e letalidade nos menores de 2 anos no período antes da introdução da vacina (2007-2010) e após a introdução da vacina (2011-2014).

RESUlTADOS Comparando-se o período pré-vacinal (2007-2010) com o pós-vacinal (2011-2014), observou-se redução das taxas de incidência da MP nos grupos de menores de 1 ano (46\%), 1 ano (32\%) e 2 anos (27\%). O mesmo ocorreu em relação às taxas de letalidade com redução de $41 \%$ no grupo de menores de 1 ano, de $78 \%$ no de 1 ano e de $33 \%$ no de 2 anos. 
CONCLUSÃO Foi possível concluir que houve redução significativa nas taxas de incidência e letalidade da MP após a introdução da vacina PNM10 no calendário nacional de vacinação no grupo de menores de 2 anos no estado do Rio de Janeiro. As reduções registradas podem não ser completamente decorrentes da vacinação em razão de outros fatores que poderiam contribuir para o declínio das taxas ao longo do tempo, porém é possível observar impacto vacinal nos grupos vacinados analisando as taxas em grupos não vacinados.

PALAVRAS-CHAVE meningite pneumocócica, vacinas, Streptococcus pneumoniae. 